\title{
Unsatisfactory performance of the leukocyte esterase test of first voided urine for rapid diagnosis of urethritis
}

From the British

Columbia Centre for Disease Control and the Division of Infectious Diseases, University of British Columbia, Vancouver, British Columbia, Canada.

D M Patrick

M L Rekart

L Knowles

Address correspondence to: Dr David M Patrick

Associate Director Division of STD Control BC Centre for Disease Control 828 West 10th Ave Vancouver, BC V5Z 1L8.

Tel: 604-660-6161

FAX: 604-775-0808

Accepted for publication 22 December 1993

\begin{abstract}
Background and Objectives-The objective of this study was to determine the performance characteristics of a dipstick test for leukocyte esterase (LE), (Chemstrip 2LN, Boehringer Mannheim) in predicting the presence of urethritis and urethral pathogens in men presenting to a busy sexually transmitted disease clinic and to street outreach facilities.

Methods-Urethral swabs for polymorphonuclear (pmn) cell count, gonorrhoea culture and chlamydia enzyme immunoassay (EIA) as well as $15 \mathrm{ml}$ of first voided urine (FVU) were collected from 737 symptomatic and 726 asymptomatic men. Gonorrhoea cultures and pmn counts were processed according to standard methods. Either Abbott Chlamydiazyme EIA (confirmed) or Syva Microtrak EIA (confirmed) test was employed to detect $C$ trachomatis. The LE test was immediately dipped in FVU, read after 60-120 seconds by the clinician and considered positive if trace, $1+$ or $2+$.

Results-Microscopic evidence of urethritis ( $\geqslant=4$ pmn cells per $1000 \times$ field) was found on urethral smear of 782 (53.5\%) patients. Chlamydia, gonorrhoea or both were present in $104(7 \cdot 1 \%)$ patients. Performance characteristics of the LE test were as follows: (table below) Conclusion-The LE test did not have adequate sensitivity to be considered a reliable rapid diagnostic test for urethritis or urethral pathogens, particularly in the asymptomatic portion of this STD clinic population.
\end{abstract}

(Genitourin Med 1994;70:187-190)

Introduction

The diagnosis of urethritis is suspected in the presence of one or more signs or symptoms

\section{All}

Symptomatic Asymptomatic

\section{Predicting urethritis} Sensitivity\% (95\% CI) Specificity \% $(95 \% \mathrm{CI})$ Pos Pred Val \% (95\% CI) Neg Pred Val \% (95\% CI Predicting gonorrhoea, chlamydia or both Sensitivity \% (95\% CI) Specificity \% (95\% CI) Pos Pred Val \% (95\% CI) Neg Pred Val \% (95\% CI)

$51 \cdot 5(48 \cdot 0,55 \cdot 0)$ $82.0(79.0,85.0)$ $82 \cdot 0(79 \cdot 0,85 \cdot 0)$
$77 \cdot 7(74 \cdot 1,81 \cdot 3)$ $58 \cdot 2(55 \cdot 0,61 \cdot 4)$

$70 \cdot 2(61 \cdot 4,79 \cdot 0)$ $66 \cdot 9(64 \cdot 4,69 \cdot 4)$ $14 \cdot 1(11 \cdot 1,17 \cdot 1)$ $96 \cdot 7(95 \cdot 5,97 \cdot 8)$
$62 \cdot 0(57 \cdot 7,66 \cdot 3)$ $73 \cdot 7(68 \cdot 1,79 \cdot 2)$ $82 \cdot 6(78 \cdot 7,86 \cdot 5)$ $49 \cdot 0(43 \cdot 9,54 \cdot 2)$ $87 \cdot 0(83 \cdot 7,90 \cdot 3)$ $65 \cdot 6(58 \cdot 0,73 \cdot 2)$
$64 \cdot 3(60 \cdot 3,68 \cdot 3)$

$74 \cdot 1(64 \cdot 8,83 \cdot 4)$ $53.0(49 \cdot 1,56 \cdot 8)$ $17 \cdot 3(13 \cdot 4,21 \cdot 2)$
$93 \cdot 9(91 \cdot 4,96 \cdot 4)$
$52 \cdot 6(30 \cdot 2,75 \cdot 1)$ $79 \cdot 6(76 \cdot 6,83 \cdot 0)$ $6 \cdot 5(2 \cdot 6,10 \cdot 5)$ $98.4(97 \cdot 4,99 \cdot 4)$ (discharge, dysuria or endourethral itch) and confirmed when a pyogenic response is demonstrated on a stained smear from a urethral swab or from the spun sediment of a first voided urine (FVU) sample. ${ }^{12}$ Many practitioners do not have early access to the results of such a stain to help in deciding whether immediate treatment should be offered to a patient with equivocal urethral symptoms.

Urine dipsticks that detect leukocyte esterase (LE) activity have seen broad use in the diagnosis of cystitis. ${ }^{3}$ Were such a rapid test to correlate accurately with the Gram stain or the presence of pathogens that require treatment, it would enable practitioners to treat confidently for urethritis while awaiting definitive bacteriological results.

Several studies have evaluated the use of LE tests on first voided urine for predicting the presence of Chlamydia trachomatis and/or Neisseria gonorrhoeae in the urethra. ${ }^{4-15}$ When LE tests were compared with the isolation of urethral pathogens by chlamydia culture or gonorrhoea culture, sensitivity ranged from $41-100 \%$ and specificity from $52-100 \%$. Many of these evaluations took place in asymptomatic or low risk populations where the strip was utilised principally for screening purposes. 579111214

Non-gonococcal urethritis requiring treatment is frequently caused by organisms other than $C$ trachomatis. ${ }^{16}$ The ability of the LE dipstick to correlate with the Gram stain for diagnosing urethritis is therefore also valuable. Fewer evaluations have published such data. Sensitivity and specificity of LE tests for a diagnosis of urethritis ranged from 78.4-100 and from $43 \cdot 2-57 \cdot 6 \%$, respectively. ${ }^{6} 1013$

Accurate estimates of sensitivity are based on sampling a large number of disease positive patients and not on total sample size. It is therefore notable that the most favourable estimates of sensitivity for chlamydial detection by the LE test are found in studies with fewer than 30 disease positive patients. ${ }^{7891113}$

We sought to determine if the LE test would function as a useful rapid diagnostic tool by accurately predicting the presence of urethritis and urethral pathogens in a trial involving sexually transmitted disease (STD) clinic and street outreach clients. Sampling of a large patient population would allow the evaluation of symptomatic and asymptomatic men and the identification of sufficient numbers of patients to have some confidence in the estimates of sensitivity and other performance characteristics. 
Methods

Male patients attending the Vancouver Sexually Transmitted Disease Clinic or one of three Street Outreach Clinics for whom screening was indicated were studied. Reasons for screening included the presence of symptoms of urethritis or of other STD, a history of contact to a person known to be infected with a STD or the presence of risk or concern related to possible acquisition of STD. Men were required not to have voided within the two hours preceding screening unless there was a frank discharge present on examination or a strong likelihood that they would not return for evaluation.

Informed consent was obtained and a directed history and physical examination were performed. A urethral swab was obtained for a smear and culture for Neisseria gonorrhoeae. A dacron swab was next inserted 3 to $4 \mathrm{~cm}$ into the urethra for chlamydia enzyme immunoassay (EIA). Fifteen $\mathrm{ml}$ of first voided urine were then collected in a plastic container.

The LE dipstick (Chemstrip 2LN, Boehringer Mannheim) was immersed in the freshly voided FVU. After 60-120 seconds, the enzymatic activity was determined by the clinician as negative, trace, $1+$ or $2+$ according to the manufacturer's colorimetric chart. The LE test was considered positive if trace, $1+$ or $2+$.

The endourethral smear was stained by the Pappenheim method and the polymorphonuclear cell count determined as described elsewhere $^{1}$ by a technologist who was not aware of the LE result.

Swabs for $N$ gonorrhoeae culture were direct plated onto Thayer-Martin medium in the clinic, placed in a $35^{\circ} \mathrm{C}$ carbon dioxide incubator and interpreted according to standard methods. ${ }^{17}$

Specimens for $C$ trachomatis EIA testing were stored at $4^{\circ} \mathrm{C}$ and tested within 48 hours with the Abbott Chlamydiazyme EIA (blocking antibody confirmed) during the first portion of the study and Syva Microtrak EIA test (fluorescent antibody confirmed) for the latter portion. The laboratory changed its standard test during the study for operational reasons. Both EIA tests were evaluated according to manufacturer's instructions except that tests with absorbance readings below but within $20 \%$ of the manufacturer's cutoff were subjected to confirmatory testing and considered positive if confirmed.

The sample size required to provide $95 \%$ confidence intervals for sensitivity of plus or minus $10 \%$, assuming a sensitivity of approximately $60 \%$, was calculated at 92 chlamydia or gonorrhoea positive patients. ${ }^{18}$ Based on the prevalence of these infections in the clinic when the study was initiated, it was judged that approximately 1400 patients would be required.

Two by two tables were constructed to compare the leukocyte esterase test result with a microscopic diagnosis of urethritis and with the isolation of chlamydia or gonorrhoea. Disease prevalence and performance charac- teristics (sensitivity, specificity, positive predictive value) were derived and recorded for each comparison. Ninety-five percent confidence intervals for these performance characteristics were calculated..$^{18}$ Similar evaluations were performed in the subsets of patients who did and who did not have symptoms, in patients within various age strata, in patients with different durations of time since their last void and using a revised definition of leukocyte esterase test as positive only if more than trace was registered. The McNemar test $^{19}$ was used to compare the results of polymorphonuclear cell count and LE test.

\section{Results}

One thousand four hundred and sixty three men were evaluated. The median age was 31 (range 15-72) years. Sexual preference was reported as heterosexual by 1258 , homosexual by 150 , bisexual by 44 and was not stated by 11 men. Urethritis symptoms (subjective impression of discharge, dysuria or endourethral itch) were reported by 737 men. The remaining 726 had no urethritis symptoms.

A microscopic diagnosis of urethritis was defined as the presence of 4 or more polymorphonuclear cells per $1,000 \times$ oil immersion field on microscopy. Microscopic urethritis was diagnosed in 782 men $(53.5 \%)$. This included 490 of 737 men with urethritis symptoms $(66.5 \%)$ and 292 of 726 asymptomatic men $(40 \cdot 2 \%)$.

The prevalence of urethral carriage of Chlamydia trachomatis as detected by enzyme immunoassay was $5 \cdot 6 \%$ ( 82 men). The prevalence of Neisseria gonorrhoeae as detected by culture was $1.8 \%$ (27 men). Either or both organisms were detected in $7 \cdot 1 \%$ (104 men).

Performance characteristics of the leukocyte esterase test in predicting the presence of microscopic urethritis are displayed in table 1. Sensitivity and specificity for predicting urethritis were $51.5 \%$ and $82.0 \%$. Sensitivity in the asymptomatic group (33.9\%) was significantly lower than in symptomatic men $(62 \cdot 0 \%)$.

Sensitivity and specificity for predicting the presence of pathogens (Neisseria gonorrhoeae, Chlamydia trachomatis or both pathogens) were $70.2 \%$ and $66.9 \%$ respectively. Sensitivity in the asymptomatic group appeared to be lower at $52 \cdot 6 \%$ but due to the

Table 1 Performance characteristic of the leukocyte esterase test on first voided urine for predicting urethritis *

\begin{tabular}{llll} 
& All patients & $\begin{array}{l}\text { Symptomatic } \\
\text { patients }\end{array}$ & $\begin{array}{l}\text { Asymptomatic } \\
\text { patients }\end{array}$ \\
\hline Sensitivity \% & $51 \cdot 5$ & $62 \cdot 0$ & $33 \cdot 9$ \\
& $(48 \cdot 0,55 \cdot 0)$ & $(57 \cdot 7,66 \cdot 3)$ & $(28 \cdot 5,39 \cdot 3)$ \\
Specificity \% & $82 \cdot 0$ & $73 \cdot 7$ & $87 \cdot 0$ \\
& $(79 \cdot 0,85 \cdot 0)$ & $(68 \cdot 1,79 \cdot 2)$ & $(83 \cdot 7,90 \cdot 3)$ \\
Positive & $77 \cdot 7$ & $82 \cdot 6$ & $65 \cdot 6$ \\
Predictive & $(74 \cdot 1,81 \cdot 3)$ & $(78 \cdot 7,86 \cdot 5)$ & $(58 \cdot 0,73 \cdot 2)$ \\
Value \% & & $49 \cdot 0$ & $64 \cdot 3$ \\
Negative & $58 \cdot 2$ & $49 \cdot 0.94 \cdot 5)$ & $(60 \cdot 3,68 \cdot 3)$ \\
Predictive & $(55 \cdot 0,61 \cdot 4)$ & $(43 \cdot 9,54 \cdot 2)$ & \\
Value \% & & & \\
\hline
\end{tabular}

*Urethritis was defined as the presence of $\geqslant=4 \mathrm{pmn}$ cells pe $1000 \times$ field on microscopy. Brackets denote $95 \%$ Confidence Intervals 
Table 2 Performance characteristic of the leukocyte esterase test on first voided urine for predicting gonorrhoea, chlamydia or both

\begin{tabular}{llll}
\hline & All patients & $\begin{array}{l}\text { Symptomatic } \\
\text { patients }\end{array}$ & $\begin{array}{l}\text { Asymptomatic } \\
\text { patients }\end{array}$ \\
\hline Sensitivity \% & $70 \cdot 2$ & $74 \cdot 1$ & $52 \cdot 6$ \\
& $(61 \cdot 4,79 \cdot 0)$ & $(64 \cdot 8,83 \cdot 4)$ & $(30 \cdot 2,75 \cdot 1)$ \\
Specificity \% & $66 \cdot 9$ & $53 \cdot 0$ & $79 \cdot 6$ \\
& $(64 \cdot 4,69 \cdot 4)$ & $(49 \cdot 1,56 \cdot 8)$ & $(76 \cdot 6,83 \cdot 0)$ \\
Positive & $14 \cdot 1$ & $17 \cdot 3$ & $6 \cdot 5$ \\
Predictive & $(11 \cdot 1,17 \cdot 1)$ & $(13 \cdot 4,21 \cdot 2)$ & $(2 \cdot 6,10 \cdot 5)$ \\
$\begin{array}{l}\text { Value \% } \\
\text { Negative }\end{array}$ & $96 \cdot 7$ & $93 \cdot 9$ & $98 \cdot 4$ \\
Predictive & $(95 \cdot 5,97 \cdot 8)$ & $(91 \cdot 4,96 \cdot 4)$ & $(97 \cdot 4,99 \cdot 4)$ \\
Value \% & & & \\
\hline
\end{tabular}

Brackets denote $95 \%$ Confidence Intervals

small number of disease positive patients, $95 \%$ confidence intervals overlapped the estimate for symptomatic patients so that this difference was not statistically significant (table 2).

Performance was not better for the prediction of chlamydia or gonorrhoea alone. For chlamydia, sensitivity and specificity were $67 \cdot 1 \%$ and $66 \cdot 2 \%$ respectively. For gonorrhoea, these estimates were $77 \cdot 8 \%$ and $65 \cdot 2 \%$ respectively.

There was no trend toward increased or decreased accuracy of the LE test with an increased time from the last void (Table 3). Patients in younger age strata were not more likely than older patients to have a more accurate result (table 4).

Considering trace results on the LE test to be negative led to estimates of sensitivity, specificity, positive predictive value and negative predictive value of $16 \cdot 6 \%, 98 \cdot 1 \%, 91 \cdot 6 \%$ and $49 \cdot 2 \%$ respectively for urethritis and $35 \cdot 6 \%, 92 \cdot 2 \%, 26 \cdot 0 \%$ and $94.9 \%$ respectively for gonorrhoea, chlamydia or both.

A polymorphonuclear cell count from the urethral smear was considered positive if 4 or more pmn cells were seen per high power field on microscopy. Sensitivity, specificity, positive predictive value and negative predictive value of the polymorphonuclear cell count were $97.6 \%, 47.9 \%, 10.4 \%$ and $99.7 \%$ respectively for chlamydia; $88.5 \%, 45.7 \%$,

Table 3 Performance characteristic of the leukocyte esterase test on first voided urine for predicting gonorrhoea, chlamydia or both by time since last void

\begin{tabular}{llll}
\hline $\begin{array}{l}\text { Time since } \\
\text { last void } \\
\text { (hours) }\end{array}$ & $\begin{array}{l}\text { Number in } \\
\text { group (number } \\
\text { disease } \\
\text { positive) }\end{array}$ & Sensitivity \% & Specificity \% \\
\hline$<2$ & $103(7)$ & 71.4 & 60.6 \\
$2-2.9$ & $755(54)$ & 75.9 & 67.7 \\
$3-3.9$ & $273(18)$ & 72.2 & 68.8 \\
$4-4.9$ & $150(10)$ & 60.0 & 63.0 \\
$5-6.9$ & $89(5)$ & 60.0 & 67.9 \\
7 or more & $93(10)$ & 50.0 & 66.7 \\
\hline
\end{tabular}

Table 4 Performance characteristic of the leukocyte esterase test on first voided urine for predicting gonorrhoea, chlamydia or both by age grouping

\begin{tabular}{lcll}
\hline $\begin{array}{l}\text { Age in } \\
\text { years }\end{array}$ & $\begin{array}{l}\text { Number in } \\
\text { Group (number } \\
\text { disease positive) }\end{array}$ & Sensitivity \% & Specificity \% \\
\hline$<20$ & $34(3)$ & $66 \cdot 7$ & $80 \cdot 7$ \\
$20-29$ & $572(69)$ & $71 \cdot 0$ & $71 \cdot 3$ \\
$30-39$ & $547(23)$ & $78 \cdot 3$ & $63 \cdot 3$ \\
$40-49$ & $225(7)$ & $42 \cdot 9$ & $64 \cdot 7$ \\
$50-59$ & $55(2)$ & $50 \cdot 0$ & $64 \cdot 2$ \\
$\geqslant=60$ & $30(0)$ & Undefined & $63 \cdot 3$ \\
\hline
\end{tabular}

$3.0 \%$ and $99.5 \%$ for gonorrhoea; and $95.2 \%$, $48.4 \%, 12 \cdot 8 \%$ and $99.2 \%$ for either gonorrhoea or chlamydia. The count detected 80 of 82 patients infected by Chlamydia trachomatis, 23 of 26 persons infected by Neisseria gonorrhoeae and 99 of 104 persons infected with either organism.

The polymorphonuclear cell count performed significantly better than the leukocyte esterase dipstick test by the McNemar test for paired proportions $(\mathrm{p}<0.001)$.

\section{Discussion}

A diagnostic test is only of value if its result serves to significantly revise the clinician's estimate of the probability of disease. Using likelihood ratios which are derived from sensitivity and specificity and applying them to a modification of Baye's theorem ${ }^{20}$, it is a simple task to predict how a test would alter such estimates (table 5). In as much as the leukocyte esterase test fails to substantially aid the clinician in predicting the presence of urethral pathogens, we would not recommend its widespread use in the STD clinic setting. Clearly, a physician would be just as accurate were she to make a therapeutic decision on the basis of symptoms alone (pre-test likelihood of microscopic urethritis in this sample was $66.5 \%$ in men with symptoms suggesting urethritis). A recent evaluation of this test in the diagnosis of mucopurulent cervicitis also found it to be unsatisfactory..$^{21}$

In this evaluation, performance characteristics of the polymorphonuclear cell count from a urethral swab were markedly superior to those of the LE test. We would do well to continue to promote office microscopy in the diagnosis and management of men at risk for urethritis.

Several factors may have contributed to a different estimate of sensitivity in this report than in other studies and may limit its generalizability. First, urine was tested immediately in the clinic rather than later in a laboratory. It is feasible that leaving leukocytes in solution over a longer period will lead to more cellular lysis and the easier detection of esterase enzyme. Overnight storage was routine in one of the evaluations of LE tests for screening asymptomatic populations in which favourable results were recorded. ${ }^{11}$ However, storing the urine prior to testing was not congruent with our aim of assessing this test as a quick aid to the clinician.

Table 5 The ability of the leukocyte esterase dipstick to revise an estimate of likelihood of urethral carriage of gonorrhoea, chlamydia or both

\begin{tabular}{clc}
\hline $\begin{array}{l}\text { Pre-test } \\
\text { likelihood }^{*}\end{array}$ & Test result & $\begin{array}{l}\text { Post-test } \\
\text { likelihoodt }\end{array}$ \\
\hline $1.0 \%$ & Positive & $2 \cdot 1 \%$ \\
$5.0 \%$ & Positive & $10.0 \%$ \\
$10.0 \%$ & Positive & $19 \cdot 1 \%$ \\
$50.0 \%$ & Positive & $67.9 \%$ \\
$1.0 \%$ & Negative & $0.5 \%$ \\
$5.0 \%$ & Negative & $2 \cdot 3 \%$ \\
$10.0 \%$ & Negative & $4.7 \%$ \\
$50.0 \%$ & Negative & $31 \cdot 0 \%$ \\
\hline
\end{tabular}

*The pre-test likelihood of disease or prevalence in a given patient population.

tThe post-test likelihood of disease given the availability of the result of the test and derived by an application of Baye's theorem. ${ }^{20}$ 
In this study, two swabs were taken prior to obtaining the urine sample and may well have depleted the amount of leukocytes present in the first voided urine. It was not considered ethically acceptable to reduce the chances of identifying Neisseria gonorrhoeae or Chlamydia trachomatis in these high risk men by taking the urine specimen first. This problem could be conceivably surmounted with respect to Chlamydia trachomatis if early reports of good sensitivity of polymerase chain reaction (PCR) on urine specimens are subsequently validated. ${ }^{22}$

The LE test may well perform better when applied to screening an asymptomatic population where there is no necessity to also take swabs from the urethra at the same time. We feel that this approach needs further evaluation with larger sample sizes. It is of note that the trial with the largest effective sample size (disease positive patients), also recorded one of the lowest estimates of sensitivity in this setting. ${ }^{12}$ Smaller volumes of first void urine may also enhance identification of esterase activity.

Urethral culture and polymerase chain reaction (PCR) are considered to be superior gold standards for the evaluation of new diagnostic tests. PCR is capable of detecting more true positives than enzyme immunoassay techniques. ${ }^{22}$ The use of enzyme immunoassay in our study may have resulted in an overestimate of false positive LE tests with a concordant adverse effect on estimates of specificity. The use of a less sensitive gold standard, however, would not be expected to similarly impair estimates of sensitivity. It was poor sensitivity that proved to be the most critical flaw identified for the LE test in this study.

There has been speculation that a leukocyte response is more predictable in younger patients ${ }^{5}$ and that the LE test would be more useful in such a population. Indeed, in one study where the LE test was found to be very effective in an asymptomatic population, the age range was $16-35 .{ }^{11}$ In our study, no age effect was demonstrable.

It is probable that LE tests produced by different manufacturers' and even different products produced by the same manufacturer may not perform alike. This needs to be taken into account when interpreting the literature on this subject. Of interest is the fact that we utilised the same product as another study showing more favourable results in a somewhat smaller population. ${ }^{11}$

Caution should be advised in interpreting some of the existing literature on LE testing. As alluded to in the introduction, it is of note that certain studies of the LE test evaluated fewer patients and certainly detected fewer with significant disease. Estimates of sensitivity were based on as few as eight disease positive patients. In addition to this concern, one must also bear in mind the frequently ignored phenomenon of publication bias. Investigators are far more likely to report the results of small studies with positive results and these are also more likely to be deemed of interest for publication by many journals.

\section{Conclusion}

This study evaluated the LE test as an aid to diagnosis in symptomatic and asymptomatic STD clinic and street outreach clients. In as much as it failed to aid the clinician in predicting the presence of urethritis or urethral pathogens, we would not recommend its widespread use in this setting.

The authors thank Ms. Fay Hutton for assistance with analysis and the staff of the Provincial Laboratory Division of Bacteriology, British Columbia Centre for Disease Control.

This work was presented, in part, at the tenth international meeting of the International Society for STD Research, Helsinki, 29 August-1 September 1993.

1 Swartz SL, Kraus SF, Herrman KL, Stargel MD, Brown WJ, Allen SP. Diagnosis and etiology of non-gonococcal urethritis. F Infect Dis 1978;138:445-54.

2 Bowie WR. Comparison of gram stain and first voided urine sediment in the diagnosis of urethritis. Sex Transm Dis 1978;5:39-42.

3 Gillenwater JY. Detection of urinary leukocytes by Chemstrip-L. F Urol 1981;125:383-4.

4 Ferris DG, Martin WH, Mathis DM, Steele JC, Fischer PM, Styslinger KM. Noninvasive detection of Chlamydia trachomatis urethritis in men by a rapid
enzyme immunoassay test. $\mathcal{F}$ Fam Pract $1991 ; 33: 73-8$.

5 McNagny SE, Parker RM, Zenilman JM, Lewis JS. Urinary leukocyte esterase test: a screening method for the detection of asymptomatic chlamydial and gonococcal infections in men. F Infect Dis 1992;165:573-6.

6 Maynaud P, Changalucha J, Grosskurth H, et al. The value of urine specimens in screening for male urethritis and its microbial etiologies in Tanzania. Genitourin Med 1992;68:361-5.

7 O'Brien SF, Bell TA, Farrow JA. Use of a leukocyte esterase dipstick to detect Chlamydia trachomatis and Neisseria gonorrhoeae urethritis in asymptomatic adolescent male detainees. Am $\mathcal{f}$ Public Health 1988;78: cent male $1583-4$.

8 Perera SAB, Jones C, Srikantha V, Ranawickrama W, Bhattacharyya MN. Leukocyte esterase test as rapid screen for non-gonococcal urethritis. Genitourin Med 1987;63:380-3.

9 Sadof MD, Woods ER, Emans SJ. Dipstick leukocyte esterase activity in first-catch urine specimens. $\mathfrak{F} A M A$ 1987;258:1932-4.

10 Schwebke JR. Use of a urine enzyme immunoassay as a diagnostic tool for Chlamydia trachomatis urethritis in men. $\mathcal{f}$ Clin Microbiol 1991;29:2446-9.

11 Sellors JW, Mahony JB, Pickard L, Jang D, Groves D, Luinstra KE, Chernesky MA. Screening urine with a leukocyte esterase strip and subsequent chlamydial testing of acy esterse strip and subsequen of asymptomatic men attending prim

12 Shafer M, Schacter J, Moscicki AB, Weiss A, Schalwitz J, Vaughan E, Millstein S. Urinary leukocyte esterase screening test for asymptomatic chlamdydial and gonoscreening test for asymptomatic chlamdydial and go

13 Veeravahu $M$, Smyth $R$, Clay J. Detection of leukocyte esterase in urine: a new screening test for nongonococcal urethritis compared with two microscopic methods. Sex Transm Dis 1987;14:180-4.

14 Werner MJ, Biro FM. Urinary leukocyte esterase screening for asymptomatic sexually transmitted disease in adolescent males. $\mathcal{F}$ Adolesc Health 1991;12:326-8.

15 White DJ, Malet RM, Bignell CJ. Non-invasive sampling method for detecting Chlamydia trachomatis. Lancet 1989;i:96-7.

16 Bowie WR. Urethritis in Males. In: Holmes KK, Mardh PA, Sparling PF, Wiesner PJ, Cates W, Lemon SM, Stamm WE, eds. Sexually Transmitted Diseases. New York: McGraw-Hill, 1990:627-9.

17 Mardh P-A, Danielsson D. Neisseria gonorrhoeae. In: Mardh P-A, Danielsson D. Neisseria gonorrhoeae. In:
Holmes KK, Mardh PA, Sparling PF, Wiesner PJ, Cates Holmes KK, Mardh PA, Sparling PF, Wiesner PJ, Cates W, Lemon SM, Stamm WE, eds. Sexually Trans

18 Arkin $C$, Wachtel $M$. How many patients are necessary to assess test performance? $\mathcal{F} A M A$ 1990;263:275-8

19 Dawson-Saunders B, Trapp RG. Basic and Clinical Biostatistics. Norwalk: Appleton \& Lange 1990:154-5

20 Rifkin RD, Hood WB. Bayesian analysis of electrocardiographic exercise stress testing. N Engl $\mathcal{f}$ Med 1977; 297:681-6.

21 Knud-Hansen CR, Dallabett GA, Reichart C, Pabst KM, Hook EW, Wasserheit JN. Surrogate methods to diagnose gonococcal and chlamydial cervicitis: comparison of leukocyte esterase dipstick endocervical gram stain and culture. Sex Transm Dis 1991;18:211-6.

22 Palmer HM, Gilroy CB, Thomas BJ, Hay PE, Gilchrist C, Taylor-Robinson D. Detection of Chlamydia trachomatis by the polymerase chain reaction in swabs and urine from men with 